\title{
Simulation Assisted Process Development for Tailored Forming
}

\author{
Bernd-Arno Behrens ${ }^{1}$, Martin Bonhage ${ }^{1}$, Dieter Bohr ${ }^{1}$ and Deniz Duran ${ }^{1} \mathrm{a}^{*}$ \\ ${ }^{1}$ Institute of Forming Technology and Machines, An der Universität 2, 30823 Garbsen, Germany \\ aduran@ifum.uni-hannover.de
}

\section{Keywords: Tailored Forming, Hybrid Materials, Induction Heating, Impact Extrusion}

\begin{abstract}
Transport industry faces challenges steadily due to rising fuel costs and stricter regulations for the emission of air pollutants. Technological developments that reduce fuel consumption are necessary for sustainable and resource-efficient transport. Innovative production technologies utilising multi-material designs come to the fore in an attempt to fabricate lightweight products with extended functionality. Departing from this motivation, novel process chain concepts for the manufacturing of bi-material forged products are being researched at the Leibniz Universität Hannover in the context of the Collaborative Research Centre (CRC) 1153. The developed technology is referred as Tailored Forming and deals with the deformation and subsequent processing of joined hybrid workpieces to produce application-oriented products. Deformation processes are carried out at elevated temperatures for thermomechanical treatment of the joining zone properties. Researchers make use of numerical simulation in each step in the process chains. This paper explains the challenges associated with induction heating and impact extrusion of bimaterial forging billets and presents our solution approaches with the aid of numerical modelling. Experimental validation results and analysis of deformed workpieces are also shown.
\end{abstract}

\section{Introduction}

Lightweighting offers new solutions to the challenge of improving fuel efficiency in the transport industry. Removing material from non-load-bearing areas, changing materials and changing heat treatment specifications are common methods being employed in the field to try to achieve weight saving. Another method is replacing the monolithic construction with a hybrid construction which provides not only lightweighting, but also the functionality of the components can be increased by utilising appropriate material in the appropriate place.

Multi-material machine components are usually fabricated by joining two or more individual parts which are already given their near-final or final form. Joining takes places towards the end of the process chain and the components are put into operation either directly or upon a finishing process. Contrary to that, researchers of the Collaborative Research Centre (CRC 1153) Tailored Forming are investigating a novel production concept, in which different materials are joined in the beginning of the process chain and then subjected to further processing, i.e., forming, machining and heat treatment. During the processing steps, joining zone properties - which are adversely affected by joining - can be treated and positively influenced. This concept brings about many process-specific challenges that need to be addressed in order to ensure reliable process chains.

The Tailored Forming process chain for the manufacturing of a bi-material stepped shaft is illustrated in Fig. 1. The first step is the fabrication of bi-material forging billets by friction welding. In the next step, billets are heated by using induction heating and formed at elevated temperatures by impact extrusion. This is followed by heat treatment and machining processes. The focus of this paper is on the processes of induction heating and impact extrusion. Numerical simulation based solution approaches developed in the course of the project are presented. 


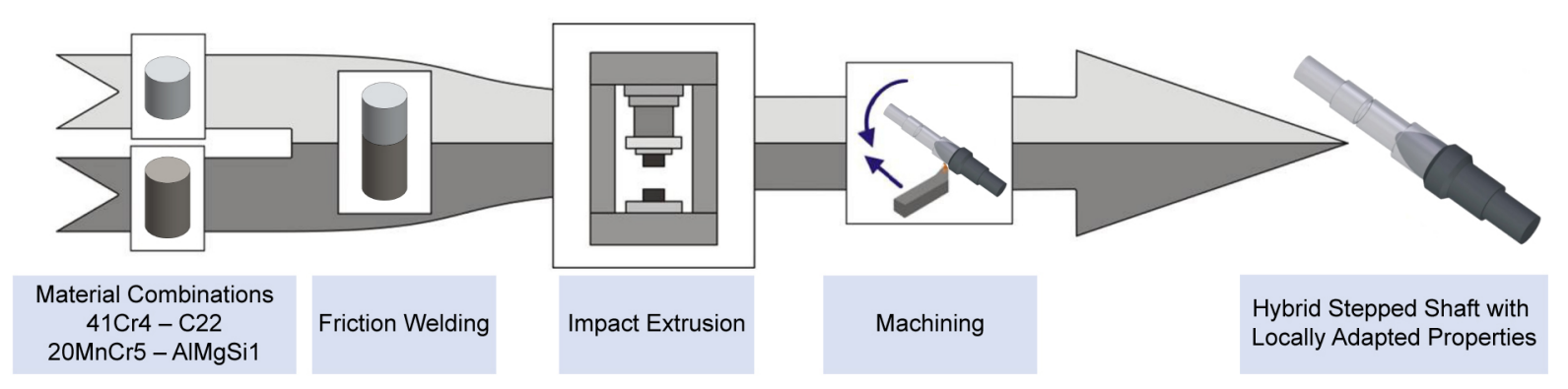

Figure 1: Tailored Forming process chain for the manufacturing of a bi-material stepped shaft [1]

\section{Survey of the Current Research Work}

Forming-related research dealing with bi-material workpiece processing are mostly gathered around the idea of achieving the compound in a single step combining joining and forming. This approach eliminates the need of a particular joining process and the coalescence is expected to take place during forming. Several studies could be found which use this approach. Wagener and Haats studied joining of metals under high pressure in cold extrusion processes [2]. It was shown that the bonding strength is directly proportional to applied degree of deformation. Rhee et al. investigated hot hydrostatic extrusion of aluminium-copper workpieces and identified the optimal processing conditions based on microstructural analyses [3]. Schlemmer and Osman studied upsetting of hollow bi-material workpieces using steel as the shell, either copper or aluminium as the core material [4]. Their intention was to locally heat the workpiece by induction and achieve intricate shapes by upsetting. Steel responded to inductive field and governed the overall heating of the workpiece. Behrens et al. combined two different steels (S355JR-42CrMo4) consecutively by spot welding and hot-forged at $1250{ }^{\circ} \mathrm{C}$. Tensile tests applied on the formed specimens showed that the strength of the joining zone is higher than the strength of the weaker material [5].

Some other studies utilise a different approach similar to the tailored blanks [6] or to the Tailored Forming concept, in which a dedicated joining process is used to manufacture bi-material workpieces. Thus, a metallurgical bond between different materials is already existent prior to the forming process. Wang et al. studied deformation behaviour of mild steel (C15) cladded with stainless steel (SAE 316L) and observed cracks in the stainless steel after hot upsetting [7]. Domblesky et al. fabricated bi-material forging billets by friction welding [8]. The flow behaviour of similar material combination (e.g., carbon steel-stainless steel) was found to be comparable; whereas with dissimilar material combination (e.g., carbon steel-copper), plastic deformation occurred mainly in the material with lower strength. Frischkorn et al. investigated hot forging of deposition-welded and friction-welded bi-material workpieces by using a forming simulator [9]. In a follow-up study, Behrens et al. applied cross wedge rolling as forming process [10]. They state that the bi-material workpieces can be formed up to high strains without any failure in the joining zone.

\section{Bi-Material Billet Manufacturing by Friction Welding}

The product in focus is a bi-material stepped shaft. The first step in the process chain is the manufacturing of bi-material forging billets by rotary friction welding. This solid-state welding process allows for joining not only similar but also dissimilar materials in the axial direction. Similar material combination includes alloy steel $41 \mathrm{Cr} 4$ and plain carbon steel C22. 41Cr4 exhibits greater yield strength and increased hardenability and thus is suited for more demanding loading conditions; whereas C22 is chosen to be low-cost structural material for non-load bearing areas. For dissimilar bi-material forging billets, $20 \mathrm{MnCr} 5$ steel is joined with AlMgSil aluminium alloy. Case hardening is generally applied to $20 \mathrm{MnCr} 5$ in order to increase its wear resistance while maintaining fair toughness in the core. AlMgSil is a variant of 6000 series aluminium alloys whose main alloying elements are magnesium and silicon. It delivers good strength-to-weight ratio upon solutionizing and artificial aging (T6). 
In the friction welding process, metallurgical bond between the materials is created via heat generation through mechanical rubbing and subsequent application of axial pressure. In steel-steel welding, steels' temperature reach above their austenitisation temperature and the joining domain becomes fully plasticised under axial pressure. This allows for the debris (oxide layer, impurities, etc.) to be displaced to the welding flash during the upsetting phase which is essential to obtain a dirt-free joining zone. In terms of steel-aluminium friction welding, the main disadvantage is their divergent plastic flow behaviour. Flow stresses of steel are significantly higher in comparison to flow stresses of aluminium. Steel remains practically rigid during friction welding which impedes its microstructural enhancement via dynamic recrystallization that is reported to be primary grain refinement mechanism in friction welding [11]. Aluminium plasticises rapidly and subjected to redundant shortening if rubbing time is held too long, as the material is displaced from the welding zone to the welding flash. Employing relatively short rubbing times is therefore common and also favourable in terms of inhibiting the growth of intermetallic compounds. These are characterised by their poor ductility and controlling their thickness is crucial in the billet manufacturing phase [12].

Before friction welding, the welding surfaces are face-turned in order to obtain plane-parallel surfaces and cleaned with a cleansing agent, respectively. The welding parameters are given in Table 1. After welding, the welding flash is removed by turning and the workpieces are cut off to their final length to finalise the bi-material forging billet fabrication.

Table 1: Friction welding process parameters for steel-steel and steel-aluminium billets

\begin{tabular}{ccccc}
\hline Material pair & $\begin{array}{c}\text { Friction } \\
\text { shortening }\end{array}$ & $\begin{array}{c}\text { Friction } \\
\text { pressure }\end{array}$ & $\begin{array}{c}\text { Forging } \\
\text { time }\end{array}$ & $\begin{array}{c}\text { Forging } \\
\text { pressure }\end{array}$ \\
\hline $\begin{array}{c}\text { Steel-Steel } \\
(41 \mathrm{Cr} 4-C 22)\end{array}$ & $4 \mathrm{~mm}$ & $60 \mathrm{MPa}$ & $6 \mathrm{~s}$ & $150 \mathrm{MPa}$ \\
\hline $\begin{array}{c}\text { Steel-Aluminium } \\
(20 \mathrm{MnCr5-AlMgSi1})\end{array}$ & $3.5 \mathrm{~mm}$ & $130 \mathrm{MPa}$ & $2 / 2 \mathrm{~s}$ & $150 / 170 \mathrm{MPa}$ \\
\hline
\end{tabular}

\section{Impact Extrusion}

Forward rod extrusion is essentially a compressive stress dominated metal forming process, yet the stress state of a material point is subjected to spatial and temporal changes during deformation. Tensile stresses also occur under certain circumstances. In the plastic deformation zone, large displacements at the outer cone lead to dragging of the centre in the reverse direction of material flow. Thus, compressive stresses at the centre gradually decrease and change to tensile stresses under plastic deformation. This is especially critical in terms of workpiece integrity in the deformation processing of joined bi-material billets. As far as their joining processes are concerned, the joining zone contains some imperfections such as gaps, regions with no bonding, etc. In the presence of tensile stresses during plastic deformation, imperfections existing in the joining zone can lead to crack emanation and propagation. These remain in the microstructure after forming and affect product properties adversely. Therefore, occurrence of tensile stresses in the workpiece should be eliminated or kept at an admissible level by constructive means. To this end, a dedicated impact extrusion tooling with counter force superposition mechanism is designed in order to have control over the stress state in the joining zone domain.

A cross sectional view of the impact extrusion tooling is shown in Fig. 2. The tooling design utilises modular floating components inside larger housings at both die and punch sides. These are fastened by using clamping rings with inner threads. By this means, a tight positioning under axial prestressing as well as self-centring is ensured. The prestressed extrusion die consists of a die insert (1.3343 high-speed steel hardened to 60-62 HRc) and two shrink rings (1.2344 tool steel, hardened to $46-48 \mathrm{HRc}$ ). Preheating of the die is carried out by using cartridge heaters embedded in the die adapter. These are connected to a temperature control unit together with a K-type thermocouple which is used for temperature monitoring. 
Below the prestressed extrusion die, the counter force superposition mechanism is situated whose main components are a transverse beam, two identical heavy duty gas springs and a counter punch. The gas springs are embedded laterally in the base plate to support the transverse beam at both ends. These are filled with nitrogen gas and the magnitude of the counter force can be controlled by adjusting the filling pressure between 50 bar and 150 bar. Gas springs are utilised as their movement is not restricted by the press movement and can travel independently. Moreover, they allow reaching relatively high forces with low space requirements and at manageable cost. The components of the counter force superposition mechanism are dimensioned in a way that by the time the joining zone starts entering the plastic deformation zone, the tip of the reduced section contacts the counter punch and start imposing downward displacements. The downward movement of the counter punch is restricted by the transverse beam due to conical mate at the centre. Thus, the imposed displacements are transmitted onto the gas springs and the resistance of the gas springs generates the required counter force. The movement begins once the initial spring force is overcome which is $85 \mathrm{kN}$ for 150 bar filling pressure. The maximum force that can be achieved is $135 \mathrm{kN}$ at the end of the spring stroke. Once the deformation stroke is completed, the punch moves back to top dead centre, the workpiece is released from the die immediately by the force of the gas springs. The ejector of the press is then actuated and pushes the formed workpiece out of the die.

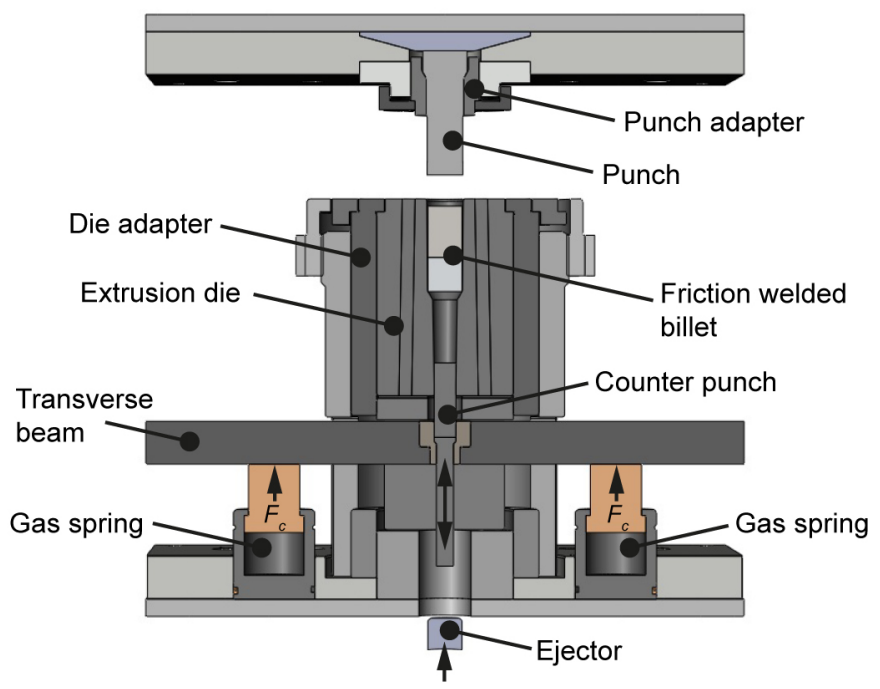

Figure 2: Tooling for impact extrusion with counter force superposition mechanism [1]

\section{Induction Heating}

The generator used in the induction heating experiments (Hüttinger TruHeat MF 3040) can operate in a mid-frequency range $(5-30 \mathrm{kHz})$ with a maximum power output of $40 \mathrm{~kW}$. An induction coil is designed and manufactured for heating steel billets with $40 \mathrm{~mm}$ diameter. The length of the coil is chosen slightly longer than the billet's total length in order to avoid overheating of billet ends due to electromagnetic end effect. Wound copper profile was wrapped with a fireresistant fabric for electrical insulation. A ceramic tube is inserted into the coil for centring of the billet.

With steel-steel billets, impact extrusion process was carried out in the warm forging domain for steel (between $700{ }^{\circ} \mathrm{C}$ and $950{ }^{\circ} \mathrm{C}$ ) in order to facilitate the recrystallization mechanisms and to match the two materials' flow behaviour by utilising their austenite state. Steel variants respond to induction heating in a similar manner because of having comparable magneto-thermal and thermophysical properties. Due to skin effect, steel surface is heated rapidly and the challenge is to generate a homogeneous temperature distribution in the radial direction via manipulating the power output of the generator and thus conducting heat to the centre without overheating the surface. In the development process of the temperature program, billet temperatures are monitored via two 
insulated rod thermocouples with a diameter of $\varnothing 1.5 \mathrm{~mm}$. These are embedded into holes that are drilled with tiny drill bits $(\varnothing 1.6 \mathrm{~mm})$, one being in the centre and the other being as close as possible to the surface. The heating steps are shown in Fig. 3 exemplarily for $900{ }^{\circ} \mathrm{C}$ target temperature. In the first sector, full generator power is utilised until the surface temperature gets near the target temperature. Then the power output is reduced gradually in consecutive sectors. In a time span of $75 \mathrm{~s}$, central and surface temperatures become equalised by the target temperature. Marginal differences are observed between $\mathrm{C} 22$ and $41 \mathrm{Cr} 4$ with the maximum difference being not more than $50{ }^{\circ} \mathrm{C}$ at the end of heating. In the last sector, the power output is increased to $30 \%$ for only $2.5 \mathrm{~s}$ in order to heat the surface above the target temperature, so that the heat losses during the transfer to the forming press can be compensated.

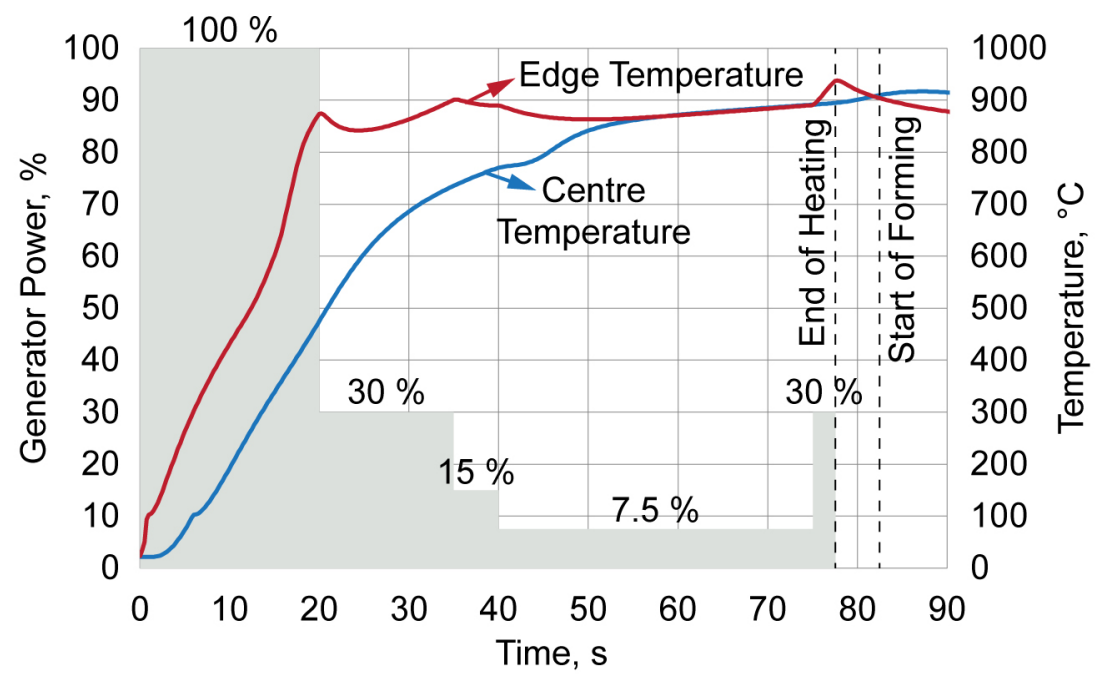

Figure 3: Heating steps determined for the induction heating of bi-material steel-steel billets;

Materials: $41 \mathrm{Cr} 4-\mathrm{C} 22$; Target temperature $=900{ }^{\circ} \mathrm{C}$

On the other hand, process-specific challenges exist for steel-aluminium billets primarily due to the fact that they exhibit vastly different flow behaviours at a given temperature. Another challenging issue is that the warm forging domain of steel is above the melting temperature of aluminium. To obtain a favourable flow in the joining zone domain, a near step-function temperature distribution in the bi-material billet is desirable. The obtained flow curves of the materials are analysed and it is found that $900{ }^{\circ} \mathrm{C}$ in steel matches $20{ }^{\circ} \mathrm{C}$ in aluminium. Modelling is carried out to develop a suitable induction heating strategy with the intention of creating an axial temperate gradient by the joining zone. The modelling results are then validated by experimental temperature readings.

The steel-aluminium billet dimensions and materials' ratio (60\% steel, $40 \%$ aluminium) are determined according to the final geometry of the shaft preform geometry and the requirements of the subsequent operations (machining, testing, etc.). The same coil which is used for heating steelsteel billets is used in the experiments.

\section{Process Modelling}

The induction heating process is modelled by Flux ${ }^{\mathrm{TM}}$ 2D: coupled electromagnetic and thermal finite element analysis software. The problem's geometry is reduced by utilising axisymmetry. Material properties are imported from the software's material library. Thermal exchange through the joining interface is enabled between the materials. Ideal thermal and electrical contact is assumed. Between air-workpiece, a convection coefficient of $10 \mathrm{~W} / \mathrm{m}^{2} \mathrm{~K}$ and an emissivity of 0.7 are assigned. 
The impact extrusion process is modelled by Marc ${ }^{\mathrm{TM}}$ : general-purpose nonlinear finite element analysis software. Flow curves of the used materials are determined by compression tests which are performed at process-relevant strain rates and temperatures [13]. A summary of the selected testing temperatures are shown in Table 2. All tests are performed at the strain rates of 1,10 and $50 \mathrm{~s}^{-1}$. The mean of three repetitive tests is calculated and assigned as the flow curve at a given temperature and strain rate. Other necessary thermo-physical properties of the materials are calculated with the CALPHAD method [14] and implemented as functions of temperature.

Table 2: Test temperatures in ${ }^{\circ} \mathrm{C}$ for the determination of materials' flow curves

\begin{tabular}{ccccccccccc}
\hline & 20 & 300 & 450 & 500 & 550 & 600 & 750 & 900 & 1050 & 1200 \\
\hline $\mathrm{AlMgSi} 1$ & $\mathbf{0}$ & $\mathbf{0}$ & $\mathbf{0}$ & $\mathbf{0}$ & $\mathbf{0}$ & $\mathbf{0}$ & & & & \\
\hline $20 \mathrm{MnCr} 5$ & $\mathbf{0}$ & $\mathbf{0}$ & $\mathbf{0}$ & & & $\mathbf{0}$ & $\mathbf{0}$ & $\mathbf{0}$ & $\mathbf{0}$ & $\mathbf{0}$ \\
\hline $\mathrm{C} 22$ & & & & & & $\mathbf{0}$ & $\mathbf{0}$ & $\mathbf{0}$ & $\mathbf{0}$ & $\mathbf{0}$ \\
\hline $41 \mathrm{Cr} 4$ & & & & & & $\mathbf{0}$ & $\mathbf{0}$ & $\mathbf{0}$ & $\mathbf{0}$ & $\mathbf{0}$ \\
\hline
\end{tabular}

In order to predict the forming behaviour accurately, the temperature fields calculated by induction heating simulation should be transferred to forming simulation. Firstly, the temperature values are exported from Flux with respect to their coordinates and saved in a formatted text file. A user subroutine is written which reads the temperature values from the text file and assigns them to the respective nodes of the new Marc mesh by means of a coordinate searching algorithm. The values are assigned as initial temperature condition over a pre-defined mesh in the beginning of forming simulation. If a finer mesh is preferred for forming simulation, initial remeshing option can be activated and the Marc mesher performs the mapping automatically.

Bi-material workpieces are modelled as deformable bodies, whereas the tooling components are described with rigid lines. In order to accurately predict the strain rate distribution in the workpiece, the press slide kinematics is recorded during the experiments by using a draw-wire displacement sensor. The portion corresponding to the deformation stroke is extracted in form of displacementtime curve and assigned as punch motion. Friction welded joining zone is represented with the glued contact condition. This means that the separation of the two materials will be suppressed, even if tensile forces take effect between them, regardless of its magnitude. Remeshing option is activated for both contact bodies due to the severity of the deformation conditions.

\section{Results and Discussion}

In the first induction heating attempt, the steel-aluminium bi-material billet is centred in the coil. It is seen that the power densities are mostly generated in steel and aluminium is heated mainly via thermal conduction. After $10 \mathrm{~s}$ of heating, aluminium temperatures already exceed $250{ }^{\circ} \mathrm{C}$. Steel surface temperatures are read around $850{ }^{\circ} \mathrm{C}$ and large radial gradients are present in the steel. As heating continues for another $10 \mathrm{~s}$, the steel end nears to the melting temperature of steel due to electromagnetic end effect and the aluminium corner adjacent to the joining zone exceeds the melting temperature of aluminium. In the second attempt, the billet is translated in the coil axially and the joining zone is positioned at the top turn of the coil. In comparison to the first attempt, aluminium temperatures can be kept significantly lower. However, steel end reaches $1200{ }^{\circ} \mathrm{C}$ after $14 \mathrm{~s}$ of heating time whilst steel temperatures by the joining zone are way below the target temperature of steel with large radial gradients. Reducing the applied power in this stage is also not beneficial as the induced power densities in the steel keep concentrating on the steel end and no significant axial gradient can be obtained by the joining zone.

The first two attempts revealed that the electromagnetic end effect should be handled in order to prevent overheating of steel end. A copper cylinder whose diameter is slightly larger than the workpiece diameter is placed below the steel to manipulate the electromagnetic field during 
induction heating. Another benefit is the heat dissipation from steel end to the copper via thermal conduction. Simulation results show that the maximum temperature field migrates to the middle section of the steel, radial temperature gradients decrease and a higher axial temperature gradient by the joining zone could be generated. Therefore, it is decided to set up the experiments in such a way as to reproduce the simulated temperature distributions in the workpiece.

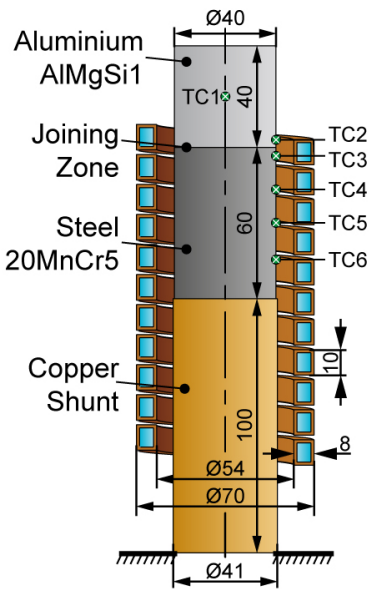

a)

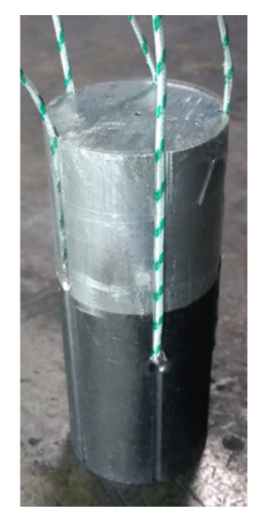

b)

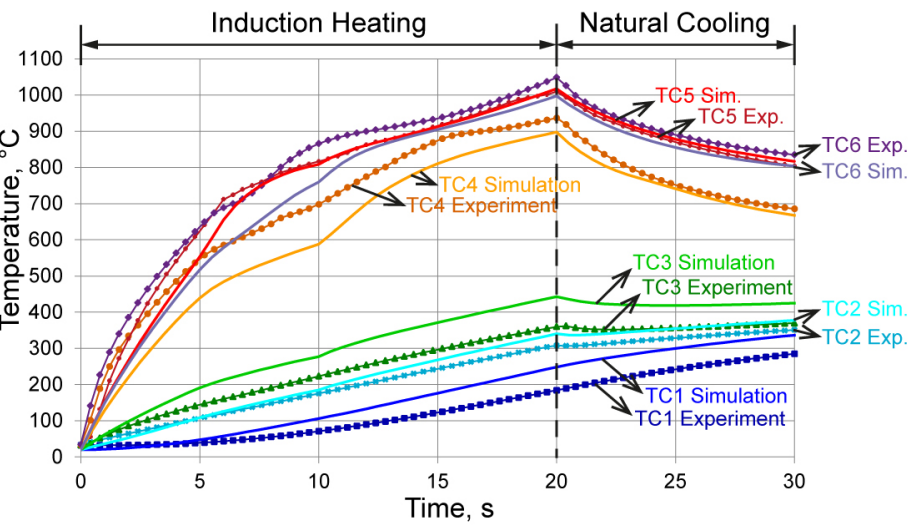

c)

Figure 4: Induction heating bi-material steel-aluminium billets (20MnCr5-AlMgSi1) [1]:

a) Experimental setup; b) Billet prepared for temperature measurement; c) Comparison between experimental temperature readings and simulation results

A schematic of the used experimental setup is shown in Fig. 4-a. A copper cylinder is machined to $41 \mathrm{~mm}$ diameter and positioned below the steel. The cylinders are translated in the inductor axially until the steel-aluminium transition is positioned by the coil's top turn. Temperature measurements are carried out by using six thermocouples (Fig. 4-b). An insulated rod thermocouple (TC1) is inserted in a blind hole in the centre of aluminium with a distance of $20 \mathrm{~mm}$ from the joining line. Five thermally insulated cable thermocouples are placed individually in $2 \mathrm{~mm}$ depth canals which are cut through along the lateral surface of the billet with an equiangular spacing. TC2 is positioned with $2.5 \mathrm{~mm}$ offset from the joining zone on the aluminium. TC3, TC4, TC5 and TC6 were placed on the steel with an offset of 2.5, 15,30 and $45 \mathrm{~mm}$ from the joining zone, respectively. Induction heating is terminated after $20 \mathrm{~s}$, by the time steel surface reaches approximately $1000{ }^{\circ} \mathrm{C}$. This is followed by pure thermal analysis for another $10 \mathrm{~s}$ to observe the balancing of temperature gradients in the workpiece. These phases are referred to as induction heating $(t=0-20 \mathrm{~s})$ and natural cooling $(t=20-30 \mathrm{~s})$, respectively. A series of induction heating experiments are conducted and it is found that using $65 \%$ of the generator power, experimental temperature readings get close to simulative predictions. Trends of the curves agree both in heating and in post-heating phases as shown in Fig. 4-c. Temperature values are also found to be in agreement with minor discrepancies. These can be explained with the correctness of boundary conditions used. Ideal contact assumption between aluminium and steel is also questionable, as the joining interface may behave like a layer with reduced conductive properties. Thorough investigations are necessary to understand this phenomenon.

Extruded workpieces are cut in longitudinal direction and etched to reveal the distinct geometrical evolution of joining zones. A comparison between the forming simulations and experiments are shown in Fig. 5. Coloured contours represent flow stresses of the materials. In forward rod extrusion, the extruded end of the workpiece falls in a dead metal zone. For the case of impact extrusion of consecutively joined bi-material billets, significant material deformation can be ensured in both materials, provided that their flow stresses match. Failing that would result in insufficient plastic deformation in the material end with higher flow stresses. Although an axial temperature gradient is generated in the steel-aluminium billets by using the developed induction 
heating strategy, the difference in the flow stresses in the joining zone domain is still prevalent during forming. As a result, plastic deformation in the steel end is relatively low and the geometrical development of the joining zone is limited (Fig. 5-a). On the other hand, better possibilities exist for similar material combinations in terms of designing the geometry of the joining zone by metal forming. Homogenous temperature distribution in steel-steel billets is utilised as steels' flow stresses match around the austenitisation temperature. The penetration of one material into the other material, which implies higher plastic straining, can be ensured as shown in Fig. 5-b exemplarily for $900{ }^{\circ} \mathrm{C}$ initial forming temperature.

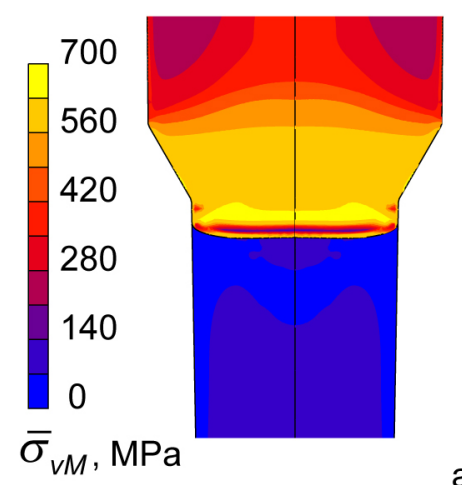

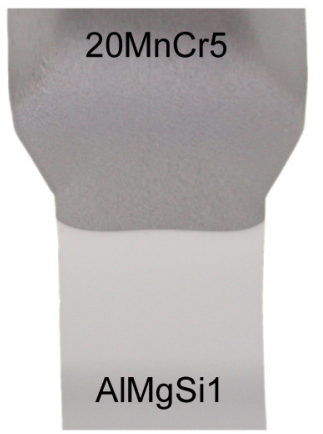

a)
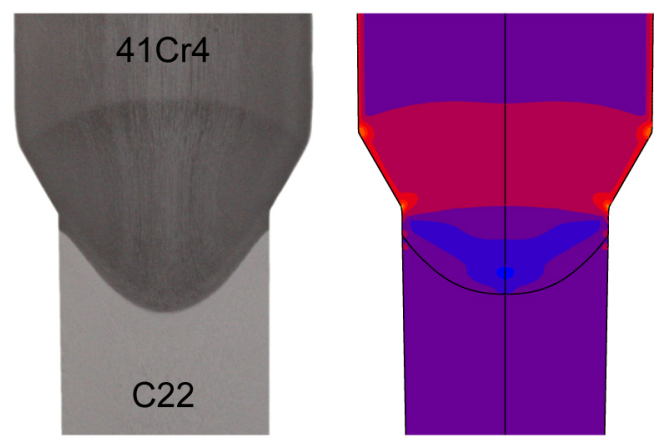

b)

Figure 5: Flow stress distributions in the bi-material workpieces (simulation) and development of the joining zones (experiment): a) Steel-aluminium workpiece (20MnCr5-AlMgSi1); b) Steel-steel workpiece (41Cr4-C22)

The influence of counter force superposition on the joining zone is also investigated for steelaluminium workpieces. No significant change is observed in the joining zone geometry after extrusion, even with the gas springs used at their maximum capacity. Only the extruded ends that are coming in contact with the counter punch become flattened. Metallographic samples are also prepared from sectioned workpieces. After polishing, the samples are etched to reveal the microstructures of steel and aluminium. Etching is first done on the steel by using a 2 percent Nital etchant. The entire sample is immersed in the etchant which is followed by water rinsing and drying. Etching procedure is repeated with 0.5 percent Hydrofluoric etchant for the aluminium. Samples are investigated under light microscope and photographs are taken of centre, half radius and edge. Two micrographs from the centre are exemplarily shown in Fig. 6.

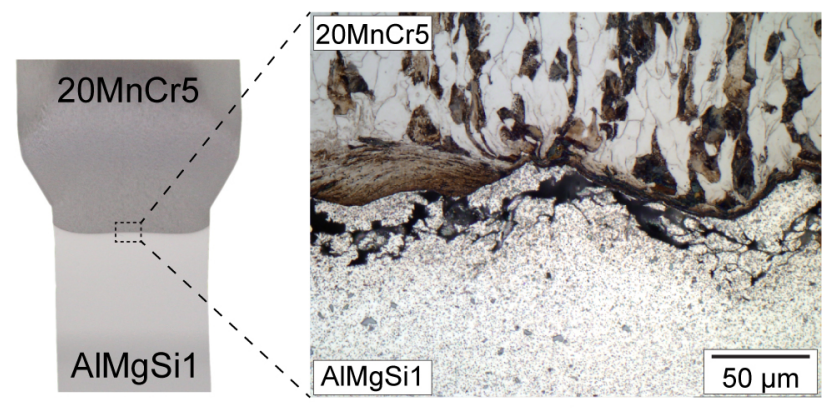

a)

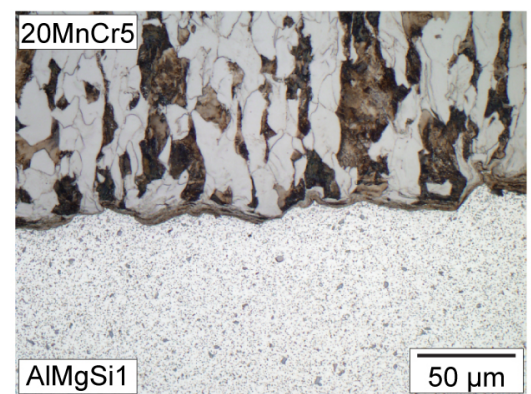

b)

Figure 6: Microstructural photographs taken of the centre of steel-aluminium workpieces: a) After extrusion without counter force superposition; b) After extrusion with counter force superposition

In general, intermetallic compounds cannot be seen under the light microscope. No gaps or cracks overall the joining zone of the friction welded sample can be observed. In the extruded samples, cracks were found at the edges of the aluminium, but away from the joining zone. These are present in both of the extruded samples - without and with counter force superposition. Simulations show excessive plastic straining in this particular location which may likely be the root 
cause of these defects. In the sample extruded with counter force superposition, a sound bonding can be traced overall the joining zone. Without the application of the counter force superposition, material separation is not seen and fissures are non-existent neither in the half radius domain nor at the outer diameter. However, in the central region, cracks in the aluminium are evident. These solely occur on the aluminium side and propagate roughly $30 \mu \mathrm{m}$ into the aluminium.

In order to account for this, the effect of the counter force superposition on the stress state is investigated by numerical simulation. Gas spring characteristics (spring stiffness, initial force to set off the movement) are read from the manufacturer's catalogue and assigned to the counter punch in the simulation. The results are evaluated according to the following procedure: First off, the interval is determined during which the joining zone is subjected to plastic deformation. This is done by tracing the equivalent plastic strain rate distribution in the workpiece. Plastic deformation takes place in the joining zone in the interval corresponding to $80 \%-98 \%$ of the whole deformation stroke. This is followed by observing the stress states as well as other important field variables in the joining zone.

Fig. 7 shows maximum principal stress profiles of the joining zone as well as the contact stresses between the materials when the deformation stroke is at $85 \%$. Tensile stresses are observed in the joining zone if counter force superposition is not used. In the practice of rotational friction welding, the relative movement between the materials converges to zero through the centreline which hinders the rubbing effect. Therefore, a metallurgical bonding at the centre is questionable in the friction welded workpieces. This might explain why cracks have occurred only in the central region but not at the half radius, where tensile stresses actually make a peak. On the other hand, by applying counter force superposition, tensile stresses can be completely eliminated. Moreover, contact stresses between the materials shift almost $200 \mathrm{MPa}$ upwards which is favourable for maintaining integrity of the materials during plastic deformation.

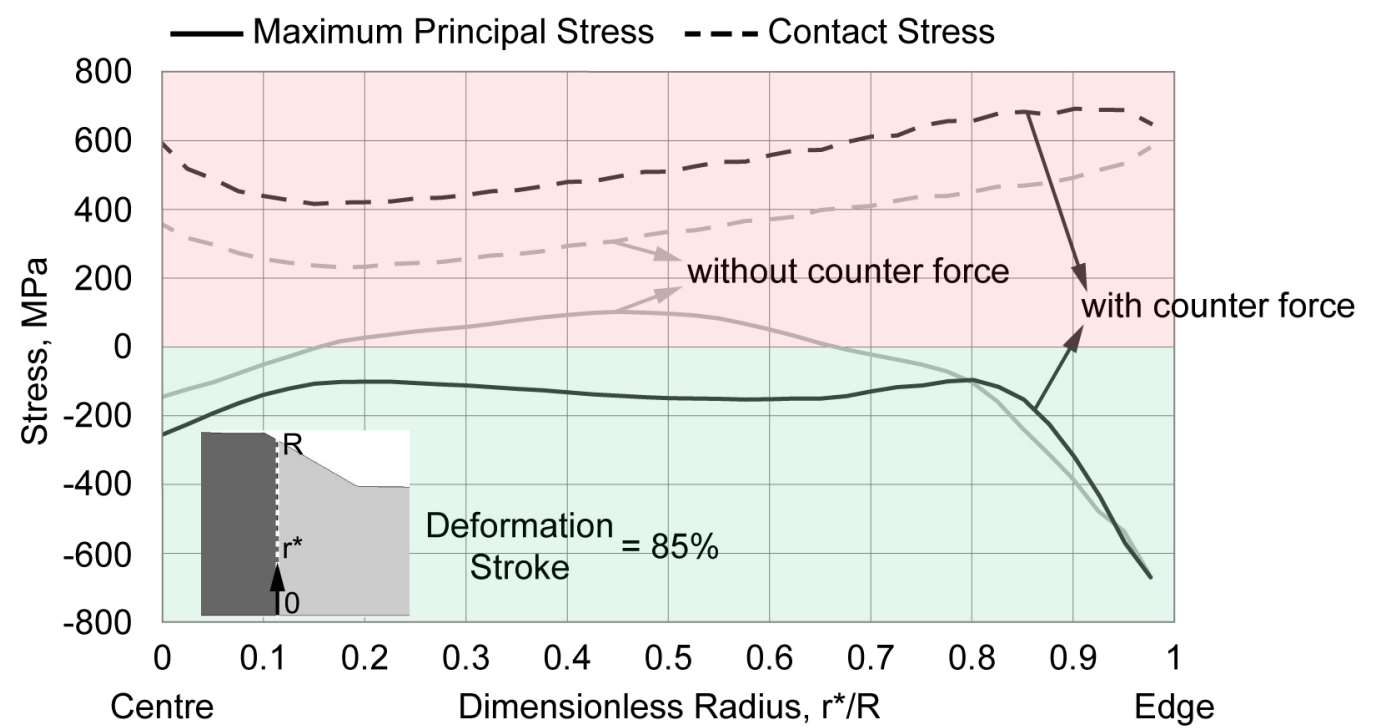

Figure 7: Maximum principal stress and contact stress profiles of the joining zone (simulation)

\section{Conclusions and Outlook}

A novel manufacturing technology referred to as Tailored Forming is presented, in which joined bi-material workpieces are utilised in process chains to fabricate load-optimised hybrid components. This study involves the process chain of a bi-material stepped shaft with the focus being on the induction heating and impact extrusion processes.

For the fabrication of bi-material forging billets, friction welding is preferred. Process details for both steel-steel and steel-aluminium workpieces are briefly explained. Induction heating is used as the heating source before the impact extrusion. Individual heating strategies are developed for steel- 
steel and steel-aluminium workpieces. Homogeneous temperature distribution in steel-steel workpieces is utilised; whereas an axial temperature gradient in the joining zone of steel-aluminium billets is generated. With regards to metal forming, a tooling concept for forward rod extrusion with counter force superposition is presented which enables controlling the stress state of the joining zone during plastic deformation. Cracks occurring in the centre of the joining zone after conventional extrusion are not observed when counter force is applied during extrusion.

Numerical simulation tools are utilised for both induction heating and impact extrusion processes. Flux ${ }^{\mathrm{TM}} 2 \mathrm{D}$ is used for the modelling of induction heating and Marc Mentat ${ }^{\mathrm{TM}}$ is used for the modelling of impact extrusion. Temperature fields calculated by Flux are imported to Marc as initial temperature condition by means of user subroutines. Thus, material flow as well as the loading profiles on the joining zone could be predicted close to reality.

A combined experimental and numerical method to predict joining zone failure is under development by another project group of CRC 1153. Moreover, it is planned to extend the scope of modelling to the entire process chain - from joining to fatigue testing - by transferring histories between the manufacturing processes. By this means, the service life of hybrid components can be expressed in advance and possible improvements in the products' life cycle can be made in the process design phase.

\section{Acknowledgments}

The results presented in this paper were obtained within the Collaborative Research Centre 1153 "Process chain to produce hybrid high performance components by Tailored Forming" in the subproject B3 (project number: 252662854). The authors would like to thank the German Research Foundation (DFG) for the financial and organizational support of this project. The authors would also like to provide thanks to Fluxtrol Inc. for providing institutional support for the project.

\section{References}

[1] Behrens, B.-A. et al., "Role of Thermal Processing in Tailored Forming Technology for Manufacturing Multi-Material Components", Heat Treat 2017: Proceedings of the $29^{\text {th }}$ ASM Heat Treating Society Conference, October 24-26, Columbus, Ohio, USA.

[2] Wagener, H.W. and Haats, J., "Pressure welding of corrosion resistant metals by cold extrusion", Journal of Materials Processing Technology, 45-1, (1994), pp. 275-280.

[3] Rhee, K.Y. et al., "Fabrication of aluminum/copper clad composite using hot hydrostatic extrusion process and its material characteristics", Materials Science and Engineering: A, 384-1-2, (2004), pp. 70-76.

[4] Schlemmer, K.L. and Osman, F.H., "Differential heating forming of solid and bi-metallic hollow parts", Journal of Materials Processing Technology, 162-163, (2005), pp. 564-569.

[5] Behrens, B.-A. et al., "Investigation of load adapted gears and shafts manufactured by compound-forging", Journal of Advanced Manufacturing Systems, 7-1, (2008), pp. 175-182.

[6] ThyssenKrupp Tailored Blanks GmbH, “Tailored Blanks Optimierte Bauteile aus Stahlblech", Product Catalogue, Issue 10, (2004).

[7] Wang, J. et al., "Study of the hot forging of weld cladded work pieces using upsetting tests", Journal of Materials Processing Technology, 214-2, (2014), pp. 365-379.

[8] Domblesky, J. et al., "Welded preforms for forging", Journal of Materials Processing Technology, 171-1, (2006), pp. 141-149.

[9] Frischkorn, C. et al., "Investigation on a new process chain of deposition or friction welding and subsequent hot forging", Materialwissenschaft und Werkstofftechnik, 44, (2013), pp. 783-789. 
[10] Behrens, B.-A. et al., "Basic study on the process combination of deposition welding and subsequent hot bulk forming", Production Engineering, 7-6, (2013),pp. 585-591.

[11] Xiong, J. et al., "Cellular automata simulation of dynamic recrystallization in rotary friction welding of pure copper", Indian Journal of Engineering \& Materials Sciences, Vol. 24, (2017), pp. 377-382.

[12] Behrens, B.-A. et al., "Co-Extrusion of Semi-Finished Aluminium-Steel Compounds", Proceedings of the $20^{\text {th }}$ International ESAFORM Conference on Material Forming, (2017), AIP Conf. Proc. 1896, 140002-1-140002-6.

[13] Behrens, B.-A. et al., "Importance of Material and Friction Characterisation for FE-aided Process Design of Hybrid Bevel Gears", Proceedings of the $20^{\text {th }}$ International ESAFORM Conference on Material Forming, (2017), AIP Conf. Proc. 1896, 190016-1-190016-7.

[14] Guo, Z. et al., "Modelling of materials properties and behaviour critical to casting simulation”, Materials Science and Engineering A, 413-414, (2005), pp. 465-469. 